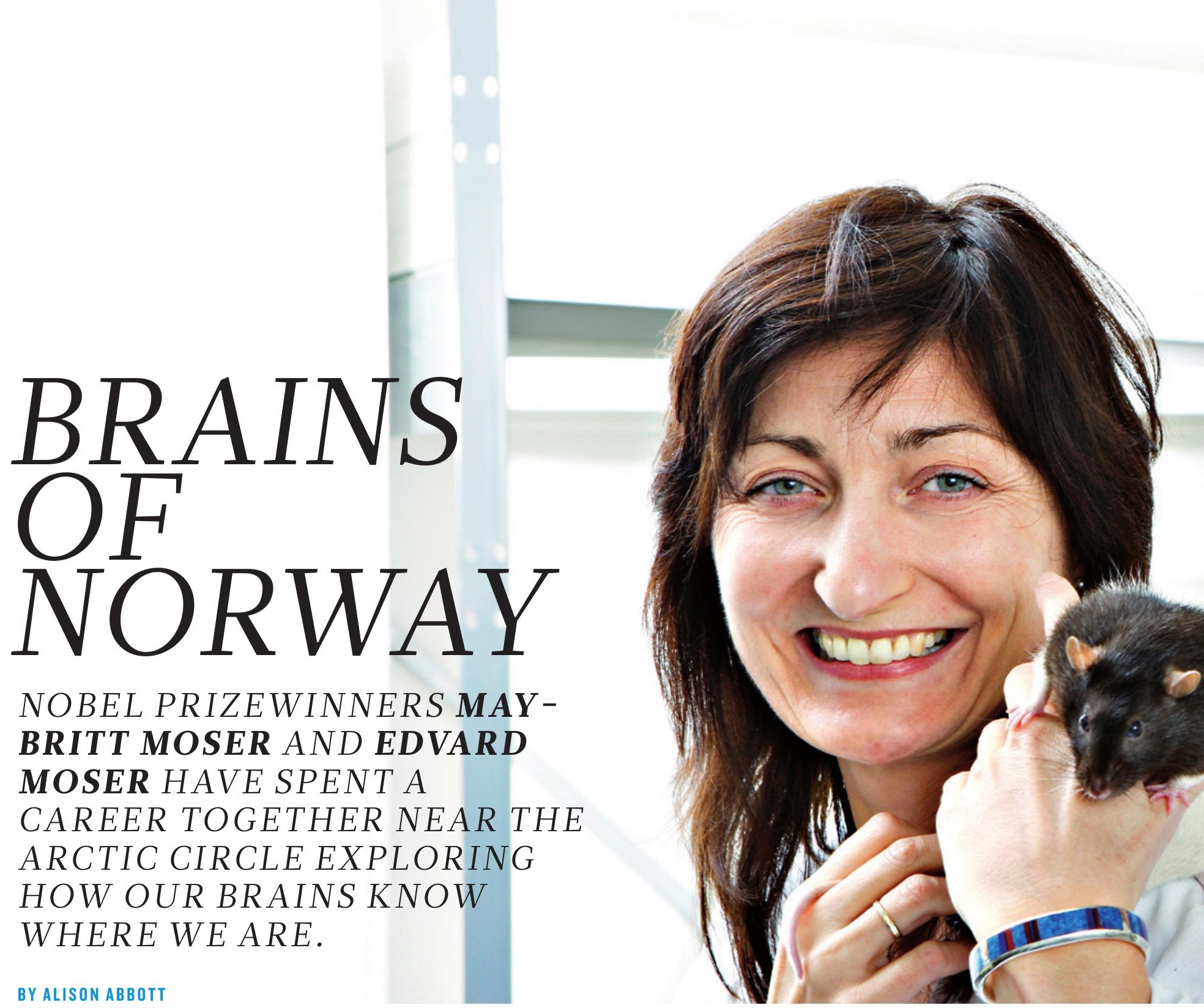

T he fact that Edvard and May-Britt Moser have collaborated for 30 years - and been married for 28 - has done nothing to dull their passion for the brain. They talk about it at breakfast. They discuss its finer points at their morning lab meeting. And at a local restaurant on a recent summer evening, they are still deep into a back-and-forth about how their own brains know where they are and will guide them home. "Just to walk there, we have to understand where we are now, where we want to go, when to turn and when to stop," says May-Britt. "It's incredible that we are not permanently lost."

If anyone knows how we navigate home, it is the Mosers. They shot to fame in 2005 with their discovery of grid cells deep in the brains of rats. These intriguing cells, which are also present in humans, work much like the Global Positioning System, allowing animals to understand their location. The Mosers have since carved out a niche studying how grid cells interact with other specialized neurons to form what may be a complete navigation system that tells animals where they are going and where they have been. Studies of grid cells could help to explain how memories are formed, and why recalling events so often involves re-envisioning a place, such as a room, street or landscape.

While pursuing their studies, the two scientists have become a phenomenon. Tall and good-looking, they operate like a single brain in two athletic bodies in their generously funded lab in Trondheim,
Norway - a remote corner of northern Europe just 350 kilometres south of the Arctic Circle. They publish together and receive prizes as a single unit - most recently, the Nobel Prize in Physiology or Medicine, which they won this week with their former supervisor, neuroscientist John O'Keefe at University College London. In 2007, while still only in their mid-40s, they won a competition by the Kavli Foundation of Oxnard, California, to build and direct one of only 17 Kavli Institutes around the world. The Mosers are now minor celebrities in their home country, and their institute has become a magnet for other big thinkers in neuroscience. "It is definitely intellectually stimulating to be around them," says neurobiologist Nachum Ulanovsky from the Weizmann Institute of Science in Rehovot, Israel, who visited the Trondheim institute for the first time in September.

The Mosers' work has also given them traction at one of the most challenging twenty-first-century research frontiers: how the brain computes. Just as computers use programming languages such as Java, the brain seems to have its own operating languages - a bewildering set of codes hidden in the rates and timing with which neurons fire as well as the rhythmic electrical activities that oscillate through brain circuits. These codes allow the brain to represent features of the external world - such as sound, light, smell and position in space - in a language that it can understand and compute. With their grid-cell work, the Mosers have been the first to crack one such code deep in the 
brain; now the challenge for the field is to find all the rest.

"May-Britt and Edvard's research lies at the very heart of the cognitive-neuroscience enterprise," says Stanislas Dehaene, who studies consciousness at the Collège de France in Paris. "They are trying to understand the neural codes for cognition - and so unite biology with computer science and even philosophy."

\section{STARS ALIGN}

The Mosers grew up on different Norwegian islands in the North Atlantic, where summer days seem eternal and the long winter nights are brightened only by the dancing Northern Lights. They were both from non-academic families and they went to the same school. But they didn't get to know each other until 1983, when both were at the University of Oslo, both were wondering what to study and both were starting to realize that their true passion was for neuroscience and the brain.

Suddenly, everything sparked: romance between the two of them, intellectual curiosity and the beginnings of their mission in life - to find out how the brain generates behaviour. The Mosers visited one of the university's more famous faculty members, electrophysiologist Per Andersen, and asked to do their undergraduate projects with him. Andersen was studying the activity of neurons in the hippocampus - a brain area associated with memory - and the two students wanted to try to link this precise activity of cells with the behaviour of animals. Andersen, like most neuroscientists at the time, was sceptical about making such a big leap across the black box of the brain. But the pair wouldn't leave his office until he gave in and offered them an apparently simple project: how much of the hippocampus could you cut away before a rat could no longer remember new environments?

The two young scientists embraced the challenge, and soon discovered something profound. Until then, it had been assumed that the hippocampus was homogeneous. But the Mosers showed that one side of it was much more important for spatial memory than the other side ${ }^{1}$. That brought home to them the importance of detailed brain anatomy for understanding brain function, a lesson that would prove invaluable later in their careers.

In 1984, while still undergraduates, the couple got engaged on top of the dormant volcano Mount Kilimanjaro in Tanzania. (The bitter temperature at the peak forced them to rush their exchange of rings, the quicker to get their gloves back on.) The pair had decided how their joint lives should be: children early, postdoc experience abroad and then their own lab together, somewhere in the world. These plans panned out - just a little faster than they had anticipated. Even before defending their PhDs, they accepted side-by-side postdocs in O'Keefe's lab in London.

In the 1970s, O'Keefe had discovered neurons called place cells in 


\section{A SENSE OF PLACE}

Edvard and May-Britt Moser study grid cells in the brain's entorhinal cortex that help animals to understand where they are.

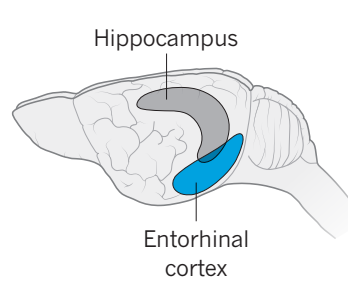

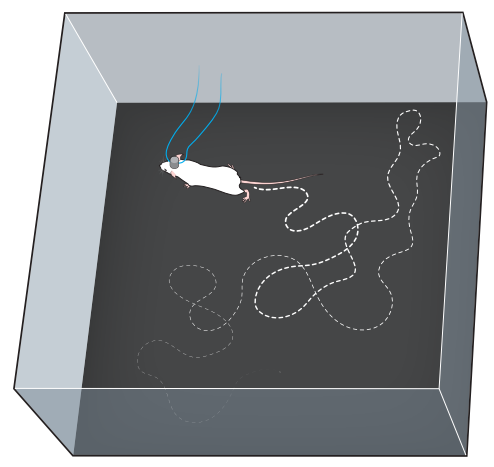

\section{RAT ON THE RUN}

The Mosers insert electrodes into a rat's entorhinal cortex and measure electrical signals from individual grid cells as the rat runs around a box, eating chocolate treats.

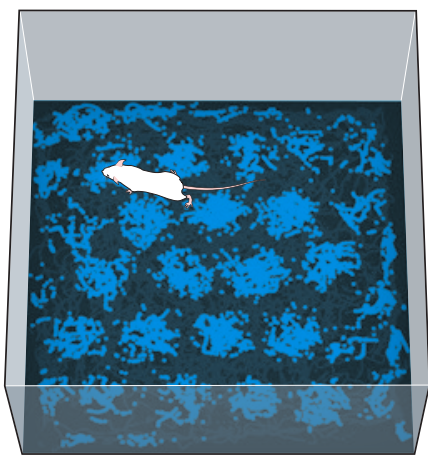

\section{FIRING PATTERN}

A single grid cell fires when a rat crosses certain points on the floor: it turns out that these points form a hexagonal grid, like a honeycomb.

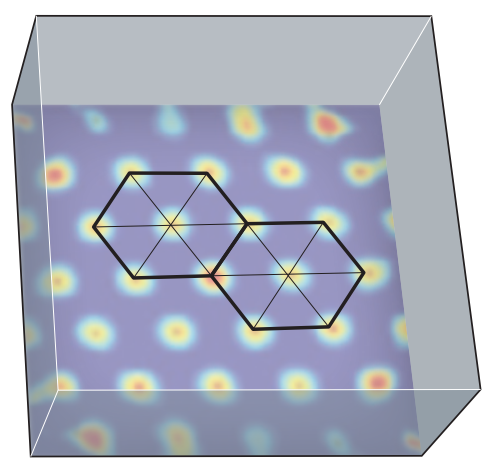

\section{POSITIONING SYSTEM}

A hexagonal pattern gives the highestpossible spatial resolution with the fewest cells. Each cell generates its own grid, and these overlapped patterns help the animal to recognize its location and direction. the hippocampi of rats. These cells fire only when an animal is in a particular place - close to an exercise wheel, for example, or in front of a door. (Since then, other navigation-related neurons have been discovered, including those that fire when the head turns in a particular direction, or when a border, such as the long edge of a cage, is in view.) The research area was red hot, and the Mosers wanted to extend it.

But in 1996, just a few months into their postdocs, the Mosers received a surprise offer of two associate professorships at the Norwegian University of Science and Technology in Trondheim. They weren't sure about accepting: it would mean striking out alone, in a small university in a country isolated from the world's major centres of research. "But the offer of two posts in the same place and in the same research area was too good to turn down," Edvard says. They flew back home, by this time trailing a toddler and baby.

It wasn't easy to get established in Trondheim. They had to build a lab from scratch in a small basement, and establish an animal facility too. But only a few years in, they were winning big grants from the European Commission and the Research Council of Norway. And by then, the results were coming through.

\section{ON THE GRID}

The pair's first aim in Trondheim had been to better describe the origin of the place-cell signal. Although the cells themselves were in the hippocampus, it could be that cells elsewhere were instructing them when to fire. Remembering their lesson from the undergraduate lab, the Mosers knew that they needed to understand the brain's anatomy to see how the signals flowed physically across it.

In the lab, they adapted the standard experimental technique for studying place cells: implanting electrodes directly into a rat's hippocampus and recording from them as the animal runs freely in a large box (see 'A sense of place'). The electrodes - which are sensitive enough to pick up activity from single neurons - feed into a computer and map the exact spot on the floor of the box where each neuron fires. This appears on screen as a black dot. To make sure that the rat covers the entire floor area, the researchers scatter chocolate treats across it. (May-Britt is a chocolate enthusiast both inside and outside the lab.)

The Mosers chemically inactivated different parts of the hippocampus and its surroundings in the rat brains, and then tested whether the place cells continued to fire normally. In this way, they discovered ${ }^{2}$ that information flowed to the place cells from the entorhinal cortex, a narrow strip of tissue running vertically up the lower back of the rat's brain. No one had paid much attention to this structure before, in large part because it is extremely difficult to access. One side lies very close to a large blood chamber; puncturing that would be fatal. The Mosers consulted an expert in neuroanatomy and concluded that, fortunately, the ideal place for the electrodes would be away from the chamber and close to the brain's surface. Then they started to repeat their experiments, recording from single neurons in the entorhinal cortex. That is when they found something unexpected.

The researchers saw that some of these entorhinal neurons fired when the rats moved onto or through a particular spot in the box, just like hippocampal place cells. But they went on to fire at several other spots too. While a rat scurried around mopping up chocolate treats, the researchers watched, perplexed, as the computer mapped the firings, and overlapping blobs appeared on the screen. The Mosers could see that the blobs were creating some sort of pattern, but they couldn't work out what it was.

It took some months before it dawned on them that they needed the rats to run around bigger boxes, so that the pattern would be stretched out and easier to see. At that point, it came into view: a near-perfect hexagon lattice, like a honeycomb. At first they refused to believe it. Such simplicity and regularity was the last thing they had expected - biology is usually a lot messier than this. But one by one, the pair ruled out all other explanations - that the pattern was an artefact from their electronic equipment, for example - and then they began to understand how this part of the brain was working. There were no physical hexagons traced on the floor; the shapes were abstractly created in the rat's brain and imposed on its environment, such that a single neuron fired whenever it crossed one of the points of the hexagon. The discovery was exciting for more than its pleasing pattern. This representation of space in brain-language was one of the long-sought codes by which the brain represents the world around us. "It was a long-drawn-out eureka moment," recalls Edvard. The team published the discovery in Nature in 2005.

\section{HIDDEN PATTERN}

Soon the Mosers were putting the grid cells to the test. They showed that the firing pattern of the cells remained constant even in the dark, and that they are independent of the animals' speed or direction $^{3}$. Whereas place cells in a rat brain may change their firing rates if their environment is altered even a little - for example by changing the colour of the walls - those of grid cells remain robustly unchanged. The Mosers also found that the different cells in the entorhinal cortex generate grids of many different types, like overlapping honeycombs - big, small and in every orientation and position relative to the box's border. And they ultimately came to see that the brain's grid cells are arranged according to a precise mathematical rule.

The cells that generate smaller grids, with narrower spacing, are at the top of the entorhinal cortex, and those that generate bigger grids are at the bottom. But it is even more exact than that: cells that make grids of the same size and orientation seem to cluster into 
modules. The modules are arranged in steps down the length of the entorhinal cortex, and the size of the grid represented by each module expands by a constant factor of 1.4 with every step ${ }^{4}$. At the same time, grid cells that represent different positions relative to the box's border are dotted randomly through the structure. Assuming a similar arrangement exists in humans, the idea is that, together, these cells are unconsciously keeping track of where we are as we wander between rooms or stroll down a street.

\section{ALL IN THE MIND}

These discoveries link the Mosers to a rich cast of scientists and philosophers who have pondered the connections between brain, memory and location since at least the time of Ancient Greece. Back then, a philosopher who needed to remember a long speech might memorize the layout of a building or a street, and mentally attach different parts of the speech to its different landmarks. He (they were almost always men) could then fluently deliver the entire rhetoric as he mentally walked around, allowing each landmark to activate the individual sections from memory. The fascination with memory and location continued into the twentieth century, when behavioural scientists first hypothesized that animals carry an abstract map of space inside their heads. The grid cells finally proved that this was true.

The discoveries also astonished and thrilled theoreticians, because the hexagonal pattern is the optimal arrangement for achieving the highest-possible spatial resolution with a minimum number of grid cells. This saves energy, showing how beautifully efficient the brain can sometimes be. "Whoever would have believed that such a beautiful hexagonal representation existed so deep in the brain?" says Andreas Herz, a computational neuroscientist at the University of Munich in Germany. "It was so unexpected that the brain would use the same simple geometric forms that we have been describing in mathematics for millennia." The appealing simplicity gives hope, he says, that the entire brain uses computational principles that scientists may eventually understand.

That understanding could take a long time to reach. It seems unlikely that the neural codes that the brain uses to represent other aspects of the world will be so simple; individual neurons may code for several different properties of the world, making the languages difficult to disentangle. The grid code is also valuable because it exists high up in the brain's hierarchy, with no direct input of sensory information. Unlike the visual cortex, say, whose coding will be influenced by light falling onto the retina, the entorhinal cortex creates the hexagonal pattern entirely internally, by integrating whatever information about the environment is received by other areas of the brain.

With the lab churning out one high-impact paper after another, the Mosers' work has attracted people and funding. Neuroscientist David Rowland was doing his $\mathrm{PhD}$ at the University of Oregon in Eugene when he read the 2005 paper on grid cells and was inspired. "I thought it was so cool that I immediately wanted my first postdoc to be in their lab," he says - and that's how it worked out. He has joined the Mosers at the Trondheim Kavli Institute, which is now buzzing with six additional research groups, each working on different aspects of neural circuitry and coding.

Not every couple would find it easy to work together in such apparent harmony. The Mosers ascribe their ability to do so in large part to their patient temperaments and shared interests - in science and beyond. Both love outdoor activities: May-Britt runs every other day across the rugged hills around their coastal home, and Edvard hikes at weekends. They share an obsession with volcanoes - hence their engagement at the top of one - and have climbed many of the globe's most spectacular peaks.

At work, they have evolved some division of labour. Edvard is more involved in computing and theory, and May-Britt manages the lab and staff and is more immersed in the experiments. "We have different strengths and we know that by combining them, the results become so much better," says Edvard. They aim for only one of them to attend any particular meeting, so that the other is left in the lab. "So we are not really stepping on each other throughout the day, as many people might believe," says Edvard.

The Mosers - and other labs around the world now studying grid cells - still have a lot to learn. Scientists do not yet know how the grid is generated by the neural networks in the entorhinal cortex, or how the overall map created by grid cells, place cells and other navigation cells is integrated to help animals to get from one place to the next. These challenges require more data, and the Mosers have a roster of experiments under way to collect them.

One virtual-reality experiment they are planning will record from

\section{"IT WAS SO UNEXPECTED THAT THE BRAIN WOULD USE THE SAME SIMPLE GEOMETRIC FORMS THAT WE HAVE BEEN DESCRIBING IN MATHEMATICS FOR MILLENNIA."}

electrodes in rats running on a stationary ball surrounded by screens showing changing environments. The rats' heads will be held still so that it becomes possible to place electrodes directly inside individual cells for the first time, and to insert small lenses that allow the researchers to simultaneously examine those cells under a microscope. This will reveal precisely which of the many cell types are firing at any one time as the rats move around the virtual space.

The next step will be to map how the grid cells are hard-wired into networks, and to find out when in the rats' lives this wiring happens. Early studies suggest that the grid system is fully established at around three or four weeks after birth ${ }^{5,6}$, which implies that babies - humans as well as rats - are born with a very primitive sense of where they are in space, and that this sense develops as their brains adapt to the world. The Mosers are also planning to test how the hexagonal pattern would be modified in the brain of a rat that has been reared from birth in a perfect sphere instead of a flat-bottomed cage.

Outside the abstract world of neural coding, grid cells have another major relevance - in understanding memory and its loss. The entorhinal cortex is the first structure in the brain to be affected by Alzheimer's disease, and getting or feeling lost is one of the disease's first symptoms. The Mosers hypothesize that the cells in the entorhinal cortex may have special properties that allow the disease to develop there early - a puzzle that they hope scientists elsewhere can start solving.

Meanwhile, in Trondheim, it is 10 p.m. and Edvard and MayBritt are still discussing the brain as they find their way home. Later, long after they are out of sight, the two scientists continue to make their presence felt. Anyone flying out of Trondheim Airport will find a photograph of the couple in an exhibition of famous Norwegians. The other 13 portraits are all of individual athletes or artists. The Mosers' portrait is the only one featuring two scientific brains. - SEE NEWS P.153

\footnotetext{
Alison Abbott is Nature's senior European correspondent.

1. Moser, E., Moser, M.-B. \& Andersen, P. J. Neurosci. 13, 3916-3925 (1993).

2. Moser, M.-B. \& Moser, E. I. J. Neurosci. 18, 7535-7542 (1998),

3. Hafting, T., Fyhn, M., Molden, S., Moser, M.-B., Moser, E. I. Nature 436 , 801-806 (2005)

4. Stensola, H. et al. Nature 492, 72-78 (2012)

5. Langston, R. F. et al. Science 328, 1576-1580 (2010).

6. Wills, T. J., Cacucci, F., Burgess, N. \& O'Keefe, J. Science 328, 1573-1576 (2010).
} 